\title{
ARTICLE
}

\section{The humanities in postgraduate medical education}

\author{
Femi Oyebode
}

\begin{abstract}
Femi Oyebode is Professor and Head of the Department of Psychiatry at the University of Birmingham. He is also a consultant psychiatrist at Queen Elizabeth Psychiatric Hospital, Birmingham. He has an interest in the use of literature in medical education. He is also a poet and a critic.

Correspondence Professor Femi Oyebode, The National Centre for Mental Health, The Barberry, Edgbaston, Birmingham B15 2SG, UK. Email: Femi.Oyebode@bsmhft. nhs.uk
\end{abstract}

\begin{abstract}
SUMMARY
This article discusses the value of the medical humanities within the medical curriculum. It explores the place of the humanities in postgraduate psychiatric training, what a curriculum might look like and which texts it might be useful to include in courses. It also briefly discusses teaching methods that may be appropriate in a postgraduate setting. Many of the proposed ideas are potentially relevant to CPD courses.
\end{abstract}

\section{DECLARATION OF INTEREST}

None.

The increasing importance of the humanities in medical education, particularly undergraduate medical education, has been commented on before in the pages of this journal (Oyebode 2002; Evans 2003). The consensus is that technological and scientific advances have created a distancing effect between patient and doctor such that the humane aspects of the field, namely empathy, compassion and the art of dealing with patients as people with distinct biographies, have been eroded. So, the argument for including the humanities within undergraduate curricula has in the main been won, even though in practice few medical students in the UK are actually exposed to much in the way of literature, history or philosophy as part of their studies. This is in contrast to the USA, where medicine is studied as a graduate subject and a substantial proportion of students come into medicine after a first degree in the liberal arts. Also, far more US medical schools teach medical humanities as a matter of course.

In undergraduate medicine, as Evans (2003) has argued, there is the imperative to 'instil and refine the medical student's scientific understanding of how the human body works - of how it contracts, develops, resists, overcomes or succumbs to disease at the physiological and anatomical levels', but medical education is more than simply this. There is the added desire that the student develop into a doctor who examines patients 'personally'. For Evans, this means 'finding out something of the salient facts of my "case" as that "case" feels to me - the person who lives the life in question'. In other words, biomedicine on its own is inadequate either as an explanatory model or as the source of knowledge for doctors in training. This is another way of saying that biomedicine does not exhaust all that is knowable about a person. There is nowhere else that this is more the case than in psychiatry. I have argued before in this journal that psychiatric disorders are pre-eminently diseases of people and not of physical organisms (Oyebode 2002).

\section{The experiencing self}

In psychiatry, the major disorders (schizophrenia and mood disorders) do not merely impair the function of the brain but exhibit themselves in behavioural disturbances that are experienced by patients and others as emanating directly from the totality of their person. These conditions are not like neurological disorders that affect motor systems or sensory systems and leave the experiencing self intact to judge and describe. The stance of the experiencing self is involved directly and intimately in psychiatric disorders. Therefore interpretative skills, an understanding of the complexity of language, and a capacity to discern the dynamics of narration and to respond meaningfully and cogently are prerequisites, at least for mastery, in psychiatry. This is to distinguish between competence, which is merely the barest minimum of clinical standards, and mastery, which is the effortless demonstration of skill at a sufficiently high level that it attracts admiration. There is thus a more compelling need in psychiatry than in other medical specialties for an appreciation of the areas of human knowledge that deal and trade in the personal, for example literature, history, linguistics and philosophy.

\section{The role of literature}

In this article I will explore what a curriculum of medical humanities in postgraduate psychiatry training exemplified by literature might look like, what texts may be relevant and whether a canon is necessary or desirable. This debate about the role and place of the medical humanities in undergraduate medicine already has recognisable parameters. It is clear in what ways literature may be useful (Box 1). It is also clear how the humanities may be deployed: either as instrumental agents where, for example, literature is a source of case histories 
depicting varying aspects of psychiatric disorders, or as a subject of importance in its own right which is therefore able to further the general education of medical students (Macnaughton 2000). Evans (2003) cogently draws this distinction between training and education. Experience has also shown that voluntary courses in the humanities are more successful than compulsory courses (Macnaughton 2000). This means that literature is more suited in undergraduate curricula to special study modules that students select because of their own interest in the subject.

\section{Medical humanities in perspective}

The Association for Medical Humanities argues that the medical humanities concern 'the nature, importance and role of human experience on the part of patients and practitioners alike, including their experience of the patient-practitioner relationship' (Arnott 2001). Furthermore, it argues for the medical humanities to be integral to and constitutive of our understanding of medicine. However, I doubt whether this can be the case. Anatomy and pathology are without doubt constitutive of medicine - one could not be a doctor without knowledge of these subjects. No matter how important medical humanities may be deemed to be, knowledge of the literary classics can hardly be regarded as central to the concern of doctors. It seems therefore clear that the medical humanities, or literature in particular, are at present optional extras that may add to the quality and calibre of doctoring but are not prerequisites for competent practice.

The aims of the medical humanities as set out by the Association for Medical Humanities include among other things:

- to emphasise education as distinct from training

- to contribute to the development of students' and practitioners' abilities to listen, interpret and communicate, and to encourage their sensitive appreciation of the ethical dimensions of practice

- to stimulate and encourage a fitting and enduring sense of wonder at embodied human nature

- to develop students' and practitioners' skills in thinking critically and reflectively about their experience and knowledge (Arnott 2001).

These are all worthy aims, but need they be encouraged only through a humanities education? It seems to me that it is possible to achieve some of these aims without recourse to the humanities. Certainly a proper understanding of physiology or pathology without regard to its expression in a novel can stimulate a sense of wonder and awe at the machinery of the body and its capacities.
B0X 1 The possible benefits of literature to medicine

- Literary accounts of illness can teach physicians concrete and powerful lessons about the lives of sick people

- Works of fiction about medicine enable physicians to recognise the power and implications of what they do

- Understanding about narrative structure can help the doctor to grasp the patient's stories of illness more fully

- Literature can contribute both the texts and methods for a study of narrative ethics

- Literary theory itself can offer a healthy counterweight to the dominant mode of understanding of texts and knowledge in biomedicine

(Charon 1995)

Clinical work properly taught and conducted can be the sole basis of an appreciation of the complexity of language such that the student comes fully to grasp the intricacies of listening to, interpreting and communicating with fellow human beings. I am not arguing against the importance or indeed the value of the humanities, I am merely attempting to establish what it is that is distinctive about the humanities. What is that extra something that would be truly missing were the humanities not to be incorporated into medicine? It seems to me that the humanities introduce into medicine the importance of the subjective, the relevance of differing perspectives and the contribution of values to decision-making. I also accept that the humanities may facilitate or act as vehicles for teaching the areas identified by the Association for Medical Humanities, while not being the sole purveyors of those areas of study.

\section{RCPsych curriculum}

The Royal College of Psychiatrists' curriculum for psychiatric specialty training does not explicitly include reference to the medical humanities (www. rcpsych.ac.uk/training/curriculum.aspx). There are competencies that have implications for the medical humanities, for example the need to demonstrate an empathic approach, to be sensitive to the effects of chronic illness on patients and their carers, and to demonstrate an understanding of how changes in society influence ethics and good practice. The curriculum does not indicate how these competencies ought to be acquired but methods derived from the humanities may be appropriate. Thus, it may be that local MRCPsych courses will choose to use autobiographical narratives, fiction, diaries, letters or film to teach these subjective and humane aspects of psychiatric practice.

In undergraduate medicine, the medical humanities appear to be more readily accepted by students when the students select them because of special and personal interest. However, there is no 
system of trainee-selected modules of learning within the current MRCPsych courses. Trainees, of course, are involved in choosing their clinical placements but the courses are not structured in such a way as to encourage choice in determining the nature of the material that trainees learn. It seems, therefore, that in postgraduate training, as opposed to undergraduate education, the humanities may need to become an integral part of teaching. It is possible to envisage a 3-hour slot within a module on major psychiatric disorders, for instance, that deals with the experience of mental illness for patients and their relatives using illustrative accounts from literature or film. The learning objectives would be:

- to demonstrate an understanding of the scope, focus, concepts, theories and controversies in the medical humanities

- to demonstrate an understanding of patients' and carers' subjective and lived experience of major psychiatric disorders.

Thus, this slot would attempt to do two things: to briefly introduce the humanities as a method of inquiry and to refine the empathic skills of the trainees.

This approach raises questions about texts that may be suitable, which indirectly leads to questions about the nature of canonical works, how these might be chosen and what the dangers are in affirming any list of books.

\section{Canonical works}

The word 'canon' derives from the Greek kanon (akin to the English 'cane'), referring to a reed. Reeds were used for measuring and in Latin and later Greek the word 'canon' meant a rule or a standard. The establishment of a canon of scriptures within Christianity, for example, was meant to define a standard or a rule for the religion. In literature, it has come to mean the texts that establish the standard by which literature in any given language is judged. In English, canonical texts would include the writings of Chaucer, Milton, Shakespeare, Dickens and Wordsworth. Traditionally, religious authority would have been vested in the Church hierarchy and the choice of texts would, by definition, reflect how the hierarchy wanted the Church to be seen. In institutions of learning, the canon would reflect also the interest of the institutional hierarchy. Thus, it is easy to see that a canon reflects and projects the interests of institutional authority and has much to do with orthodoxy. However, there are advantages too: a canon specifies the collection of works that best represent a genre and even though these works are not unified by much other than language, culture and historical epoch, the canon establishes the parameters that define the form.
In a world that has become less respectful of authority, the very idea of a canon has come under attack. Simply put, canons that exclude the voices of marginal communities or of women or indeed of minorities are said not to speak to the richness of society. Thus, any attempt to identify a list of literary texts is problematic not merely for fear that it would be attacked but also because there is no objective, unprejudiced selection method. Despite the anxiety that any proposed list of works may be subjected to criticism and challenge, there is a case for suggesting a tentative list of texts that allows for courses to have a framework to introduce the study of literature into medicine.

Texts can be chosen for each of the different roles listed in Box 1. Clearly, this list is tentative and open to revision.

\section{Personal accounts}

Literary accounts of psychiatric illness can be exemplified by texts that describe first-hand experience of mental distress. These texts could include autobiographical accounts (Oyebode 2003), letters (Oyebode, 2009a) and diaries. These accounts usually have a directness and freshness uninhibited by psychiatric constructs and unconstrained by the theory-laden questioning of psychiatric interviews. Then there are fictional accounts (Oyebode 2004) and poetry written by people who have had primary experience of mental distress (Oyebode, 2009b). These fictional accounts, although based on personal experience, have the advantage that the author is able to freely consider issues that may have been too painful if discussed as personal in origin (Box 2). Works of autobiography or fiction that deal with the power and implications of what doctors do are similar and related to literary accounts described above in as much as they are depictions of the role of doctors and the manifold complexity of that role (Box 3).

\section{Repeated themes}

Narrative theory assumes that there is a finite number of underlying basic themes despite the apparent multiplicity and heterogeneity of myths in the world. In other words, it assumes that there are constant, underlying structures in myths that are universal in nature and that are recombined much in the way that language itself is built up from underlying basic units. It is therefore possible to see archetypal figures in myths, including the hero, the villain, the damsel in distress and the numerous obstacles that have to be surmounted before her rescue can occur. A full description of these ideas is outside the scope of this article but interested readers will find that Eagleton (1983) provides a good introduction. 
BOX 2 Literary accounts of illness

\begin{tabular}{|c|c|c|}
\hline Autobiographies & Memoirs of my Mental IIIness (Daniel Schreber & Diary of a Madman (Nikolai Gogol 1834) \\
\hline A Guard Within (Sarah Ferguson 1973) & 1903) & Don Quixote de la Mancha (Cervantes 1605) \\
\hline A Mind that Found Itself: An Autobiography & Malignant Sadness. The Anatomy of Depression & Jane Eyre (Charlotte Brontë 1847) \\
\hline (Clifford Whittingham Beers 1908) & (Lewis Wolpert 1999) & Scar Tissue (Michael Ignatieff 1993) \\
\hline A Narrative of the Treatment Experienced by a & $\begin{array}{l}\text { Out of Me. The Story of a Postnatal Breakdown } \\
\text { (Fiona Shaw 1997) }\end{array}$ & Shame (Salman Rushdie 1983) \\
\hline (John Perceval 1840) & The Scent of Dried Roses (Tim Lott 1996) & Spider (Patrick McGrath 1990) \\
\hline An Autobiography (Janet Frame 1990) & & The Bell Jar (Sylvia Plath 1963) \\
\hline An Unquiet Mind. A Memoir of Moods and & & The Kreutzer Sonata (Leo Tolstoy 1889) \\
\hline Madness (Kay Redfield Jamison 1995) & to Felıce (Fran & The Sound and the Fury (William Faulkner 1929) \\
\hline Asylum (William Buehler Seabrook 1935) & $a t$ & The Yellow Wallpaper (Charlotte Perkins Gilman \\
\hline Autobiography (John Stuart Mill 1873) & Fiction & 1892) \\
\hline Darkness Visible. A Memoir of Madness (William & Asylum (Patrick McGrath 1996) & \\
\hline Styron 1990) & Barnaby Rudge (Charles Dickens 1840-1) & \\
\hline
\end{tabular}

The relevance of this for psychiatry is that patients structure their accounts using the same basic elements: the hero who is fighting the medical services for justice; the villain who has been so identified by family or spouse but is really a hero; and the damsel in distress waiting for her rescuer. It seems obvious that to fully grasp the narrative structure of an account, there is a need to distance oneself from the immediacy of the actual detailed content. Novels that are explicitly based on narrative theory are perhaps ideal for illustrating the nature and power of narrative structure. A good example of this is Bernhard Schlink's novel Homecoming (2006), in which he utilises the narrative structure of homecoming after a war and sets his story in

BOX 3 Depictions of the roles of doctors

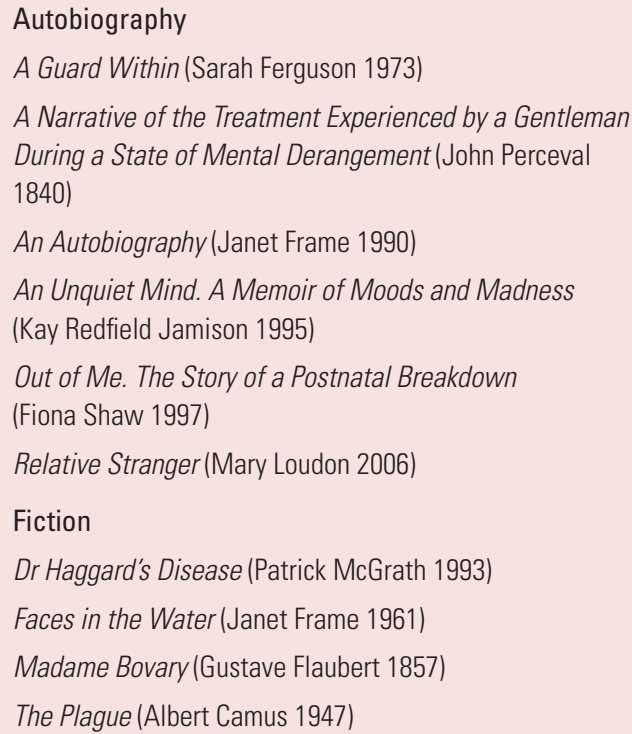

post-war Germany. The story explores homecomings in general and as a specific German phenomenon, and of course alludes to Homer's Odyssey. Although it has no direct bearing on psychiatry, the novel provides an opportunity to understand and discuss the force of narrative structure on day-to-day storytelling.

\section{Ethics from literature}

Narrative ethics is the use of a literary text to study the underlying ethics of a story. It is a sophisticated method for discussing ethics that builds on the use of clinical cases in which the ethical dilemmas are often limited to clinical ethics. The use of literary texts in this context allows a richer and nuanced discussion and awakens the trainee's sensitivity to ethical questions in daily life. For example, Albert Camus' novel The Plague (1947) can be read on several levels. Certainly, it deals with the question of the doctor's responsibility in the face of an infectious disease, in this case the plague, to which he too is vulnerable, and it has been interpreted as an allegory for the French resistance movement during the occupation of France by Germany in the Second World War. It can also be used as a basis for discussing the nature and limits of the duty of beneficence as opposed to the principle of nonmaleficence.

\section{Applying literary theory}

Developments in literary theory during the past century have encompassed psychoanalysis, structuralism, deconstruction, Marxist theory and many other theories. These influence wider society well beyond their narrow interest to literary scholars. To take but one example, deconstruction refers to the way that systems of meaning are based on 
unexpressed binary structures. Our notion of 'man' is constrained by our notion of 'woman' and the reverse is also true. This is more than simply saying that a man is the opposite of a woman, for it is saying that a woman is 'non-man'. These binary systems of thinking usually involve opposites, constructed along the dimension of what is acceptable and what is not: self and non-self; sense and nonsense; reason and madness; central and marginal; surface and depth. What is the value of this to psychiatry? It is instructive in that it alerts a trainee to the unspoken, underlying assumptions in textbooks. All texts have a standpoint - the hinge that makes it possible for the reader to open and shut the door, that is, to let light into the text. Some awareness of this will at least allow the trainee to be wary. The writings of Edward Said, particularly in Orientalism (1978), and Chinua Achebe in Hopes and Impediments (1988) are good introductory sources.

\section{Methods of teaching}

How should the humanities be taught? The purpose of adding the humanities to the psychiatric curriculum is not to teach facts; rather, it is to teach trainees different ways of seeing the world. Thus, the most important task is to encourage curiosity, discussion and a critical attitude. This should mean working in small groups, with trainees expected to do prior reading and to be prepared to actively contribute to discussions within the group. It is a sad reflection on current teaching in psychiatry that trainees expect to be lectured to, predominantly about facts that appear relevant to examinations. Any deviation from subjects and themes that have ready answers and that are not amenable to assessment by multiple choice questions is usually deemed irrelevant. The humanities cannot be taught in this way.

\section{Preparation for group discussion}

One model is for trainees to read selected passages before the seminar, with prompts that suggest questions and areas that deserve further inquiry (Box 4). At the start of the seminar, some introduction to the biography and works of the chosen author and the background to the selected passage can be briefly given. Trainees can then work in groups of three or four to discuss the passage and prepare their responses to the prompts for further discussion in the plenary session of the seminar.

\section{Using film}

It is possible to extend the richness of a literary passage by choosing a work that has been made into a film. This allows for further discussion about the merits of the filmic interpretation, the character of the portrayal and representation of mental illness, and the differing impact of literature and of film. The discussions that emerge from such sessions are difficult to test within current assessment programmes. This is not to say that difficulty assessing particular modes of comprehension is

B0X 4 Extract from Schreber's Memoirs of my Nervous IIIness (1955: p. 33)

Open letter to Professor Flechsig

March 1903

Dear Professor,

I take the liberty of enclosing a copy of "Memoirs of a Patient Suffering from a Nervous IIIness", which I have written, and beg you to examine it in a kindly spirit.

You will find your name mentioned frequently, particularly in the first chapter, partly in connection with circumstances which might be painful to you. I very much regret this but unfortunately cannot make any changes without from the very outset precluding making myself understood. In any case it is far from me to attack your honour, as indeed I do not harbour any personal grievance against any person [Schreber's italics]. My aim is solely to further knowledge of truth in a vital field, that of religion.

I am absolutely certain that in this regard I command experiences which when generally acknowledged as valid will act fruitfully to the highest possible degree among the rest of mankind. Equally I have no doubt that your name plays an essential role in the genetic development of the circumstances in question, in that certain nerves taken from your nervous system became "tested souls" in the sense described in Chapter I of the "Memoirs", and in this capacity achieved supernatural power by means of which they have for years exerted a damaging influence on me and still do to this day. You like other people may be inclined at first to see nothing but a pathological offspring of my imagination in this; but I have an almost overwhelming amount of proof of its correctness, details of which you will find in the content of my "Memoirs". still feel daily and hourly the damaging influence of the miracles of those "tested souls"; the voices that speak to me even now shout your name again and again at me hundreds of times every day in this context, in particular as the instigator of those injuries; and this despite the fact that the personal relations which existed between us for some time have long since receded into the background for me; I could hardly therefore have any reason to keep thinking of you, especially with any sense of grievance.

\section{Group task questions}

1 What is the nature of Schreber's perception of his relationship with Professor Fleschig?

2 What psychopathological phenomena are described in this passage?

3 What does this passage teach us about the nature of insight in psychiatry? 
evidence that the knowledge and understanding thus acquired are in some way inferior or less exacting.

\section{Conclusions}

The value of the medical humanities to undergraduate medical education is now well established, even if the implementation of courses is patchy across medical schools in the UK. However, there has been little discussion about medical humanities in postgraduate training, and many of the ideas considered in this article are relevant to CPD courses.

\section{References}

Achebe C (1988) Hopes and Impediments. Heinemann.

Arnott R, Bolton G, Evans M, et al (2001) Proposal for an academic Association for Medical Humanities. Journal of Medical Ethics: Medical Humanities; 27: 104-5.

Camus A (1947) The Plague (trans S Gilbert). Hamish Hamilton.

Charon R, Trautmann Banks J, Connelly JE, et al (1995) Literature and medicine. Contributions to clinical practice. Annals of Internal Medicine; 122. 599-606.
Eagleton T (1983) Literary Theory. Blackwell Publishing.

Evans M (2003) Roles for literature in medical education. Advances in Psychiatric Treatment, 9: 380-5.

Macnaughton J (2000) The humanities in medical education. Context, outcomes and structures. Journal of Medical Ethics: Medical Humanities; 26: 23-30.

Oyebode $\mathrm{F}$ (2002) Literature and psychiatry. Advances in Psychiatric Treatment, 8: 397-8.

Oyebode F (2003) Autobiographical narrative and psychiatry. Advances in Psychiatric Treatment, 9: 265-70

Oyebode F (2004) Fictional narrative and psychiatry. Advances in Psychiatric Treatment, 10: 140-5.

Oyebode F (2009a) Letters and psychiatry: the case of Franz Kafka. In Mindreadings (ed F Oyebode): pp 68-77. RCPsych Publications.

(Oyebode, 2009b) Poetry and psychiatry. In Mindreadings (ed F Oyebode): pp 55-67. RCPsych Publications.

Said E (1978) Orientalism. Routledge \& Kegan Paul.

Schreber DP (1955) Memoirs of My Nervous IIIness (trans I Macalpine, RA Hunter). Wm Dawson \& Sons.

Schlink B (2006) Die Heimkehr. English translation (2007) Homecoming (trans MH Heim). Weidenfeld \& Nicolson.

\begin{tabular}{|lllll|}
\hline \multicolumn{7}{|l|}{ MCO answers } \\
1 & 2 & 3 & 4 & 5 \\
at & af & af & af & af \\
bf & bt & bf & bf & bt \\
cf & cf & cf & cf & cf \\
df & df & dt & dt & df \\
ef & ef & ef & ef & ef \\
\hline
\end{tabular}

\section{MCQs}

1 Medical humanities include:

a literature

b physiology

c pathology

d nephrology

e statistics.

\section{Medical humanities can:}

a give an understanding of physiology

b illustrate the lives of sick people

c demonstrate the power and influence of genes

d teach narrative ecology

e exemplify theory of mind.
3 The aims of the Association for Medical Humanities include:

a teaching in small groups

b acquiring historical artefacts for undergraduate teaching

c recognising the importance of community medicine

d emphasising the distinction between education and training

e facilitating evidence-based medicine.

4 Canonical works:

a are written by canons

b contain the wisdom of a culture c establish the standard of reading

d in English would include the works of Shakespeare

e have been criticised for excluding male poets.

5 Narrative ethics:

a include applying the concept of deconstruction

b can form the basis for teaching clinical ethics

c apply narrative theory to help understand epistemology

$d$ have no place in medicine

e are a version of virtue theory. 